\title{
Haplogroup T Is an Obesity Risk Factor: Mitochondrial DNA Haplotyping in a Morbid Obese Population from Southern Italy
}

\author{
Carmela Nardelli, ${ }^{1,2}$ Giuseppe Labruna, ${ }^{3}$ Rosario Liguori, ${ }^{1,2}$ Cristina Mazzaccara, ${ }^{1,2}$ \\ Maddalena Ferrigno, ${ }^{1}$ Valentina Capobianco, ${ }^{1,2}$ Massimo Pezzuti, ${ }^{1,2}$ \\ Giuseppe Castaldo, ${ }^{1,2}$ Eduardo Farinaro, ${ }^{4}$ Franco Contaldo, ${ }^{5}$ Pasqualina Buono, ${ }^{3,6}$ \\ Lucia Sacchetti, ${ }^{2,7}$ and Fabrizio Pasanisi ${ }^{5}$ \\ ${ }^{1}$ CEINGE Biotecnologie Avanzate S.C. a R.L., Via G. Salvatore 486, 80145 Naples, Italy \\ ${ }^{2}$ Dipartimento di Medicina Molecolare e Biotecnologie Mediche, Università degli Studi di Napoli Federico II, \\ Via S. Pansini 5, 80131 Naples, Italy \\ ${ }^{3}$ IRCCS Fondazione SDN, Istituto di Ricerca Diagnostica e Nucleare, Via E. Gianturco 113, 80143 Naples, Italy \\ ${ }^{4}$ Dipartimento di Sanità Pubblica, Università degli Studi di Napoli Federico II, Via S. Pansini 5, 80131 Naples, Italy \\ ${ }^{5}$ CISRO, Centro Interuniversitario di Studi e Ricerche sull'Obesità e Dipartimento di Medicina Clinica e Chirurgia, \\ Università degli Studi di Napoli Federico II, Via S. Pansini 5, 80131 Naples, Italy \\ ${ }^{6}$ Dipartimento di Studi delle Istituzioni e dei Sistemi Territoriali, Università degli Studi "Parthenope", Via F. Acton 38, \\ 80133 Naples, Italy \\ ${ }^{7}$ Laboratori Misti, IRCCS Fondazione SDN-CEINGE, Via E. Gianturco 113, 80143 Naples, Italy
}

Correspondence should be addressed to Lucia Sacchetti; sacchett@unina.it

Received 30 April 2013; Accepted 3 June 2013

Academic Editor: Ashraf S. Gorgey

Copyright (c) 2013 Carmela Nardelli et al. This is an open access article distributed under the Creative Commons Attribution License, which permits unrestricted use, distribution, and reproduction in any medium, provided the original work is properly cited.

\begin{abstract}
Mitochondrial DNA (mtDNA) haplogroups have been associated with the expression of mitochondrial-related diseases and with metabolic alterations, but their role has not yet been investigated in morbid obese Caucasian subjects. Therefore, we investigated the association between mitochondrial haplogroups and morbid obesity in patients from southern Italy. The mtDNA D-loop of morbid obese patients $\left(n=500 ; \mathrm{BMI}>40 \mathrm{~kg} / \mathrm{m}^{2}\right)$ and controls $\left(n=216 ; \mathrm{BMI}<25 \mathrm{~kg} / \mathrm{m}^{2}\right)$ was sequenced to determine the mtDNA haplogroups. The T and J haplogroup frequencies were higher and lower, respectively, in obese subjects than in controls. Women bearing haplogroup $\mathrm{T}$ or $\mathrm{J}$ had twice or half the risk of obesity. Binomial logistic regression analysis showed that haplogroup $\mathrm{T}$ and systolic blood pressure are risk factors for a high degree of morbid obesity, namely, BMI $>45 \mathrm{~kg} / \mathrm{m}^{2}$ and in fact together account for $8 \%$ of the BMI. In conclusion, our finding that haplogroup T increases the risk of obesity by about two-fold, suggests that, besides nuclear genome variations and environmental factors, the $\mathrm{T}$ haplogroup plays a role in morbid obesity in our study population from southern Italy.
\end{abstract}

\section{Introduction}

Obesity is a multifactorial disorder caused by a combination of environmental, behavioural, and genetic factors; however, the molecular mechanisms by which these factors provoke fat mass accumulation and maintenance are not yet completely elucidated [1]. Moreover, mitochondrial dysfunctions that result in lipid accumulation and insulin resistance have been implicated in the pathogenesis of obesity [2]. Several mitochondrial DNA (mtDNA) variants have been investigated in diverse populations with obesity-related and lipid metabolism alterations $[3,4]$, and it was suggested that particular mtDNA haplogroups could be associated with inefficient energy expenditure [5]. A mitochondrial haplogroup (mt-haplogroup) is a collection of single nucleotide polymorphisms [6] accumulated throughout human history 
in specific populations that could be attributed to genetic drift and/or climate selection [7-9]. Mitochondrial haplogroups have been associated with the expression of mitochondrialrelated diseases (metabolic syndrome, type 2 diabetes, neurological disorders, infertility, and Parkinson's disease) and with various individual characteristics (aging and endurance training capacity) [3, 10-14], but, to our knowledge, their role has not yet been investigated in morbid obese Caucasian subjects. We previously reported that several DNA variants and epigenetic alterations are associated with the obese phenotype and/or with obese-related diseases [15-19]. Here, we have characterized mt-haplogroups in a large population of morbid obese adults and nonobese individuals from southern Italy to look for associations among specific mt-haplogroups and the obese phenotype.

\section{Methods}

2.1. Study Population. Five hundred unrelated morbid obese patients (64\% females, age range $17-70$ years, median; 2.5 th97.5th percentiles $\mathrm{BMI}=45.1 ; 38.2-65.4 \mathrm{~kg} / \mathrm{m}^{2}$ ), and 216 non obese controls $(66 \%$ females, age range $26-76$ years, BMI $=22.9 ; 18.2-25.6 \mathrm{~kg} / \mathrm{m}^{2}$ ) were recruited from the Obesity Outpatient Clinic of the Dipartimento di Medicina Clinica e Chirurgia and from the Dipartimento di Medicina Molecolare e Biotecnologie Mediche, Federico II University Hospital, Naples (Italy), respectively. All participants were Caucasians and had lived in southern Italy for at least 3 generations. Written informed consent for participation in the study was obtained from all subjects. The research was approved by the Ethics Committee of the School of Medicine, University of Naples Federico II, and was in accordance with the principles of the Helsinki II Declaration.

2.2. Laboratory Investigations. Two blood samples (one for biochemical analysis and one for DNA extraction) were obtained after an overnight fast from each enrolled subject. Biochemical parameters were measured enzymatically with routine methods on an automated analyzer (Hitachi 747; Boehringer Mannheim, Germany). Insulin resistance was estimated in obese subjects with the homeostasis model assessment (HOMA) and the formula: fasting insulin (mU/L) $\mathrm{X}$ fasting glucose $(\mathrm{mmol} / \mathrm{L}) / 22.5$.

The clinical and anamnestic data of each obese subject were collected, and the main metabolic parameters were evaluated. Fat mass (FM) and fat-free mass (FFM) were measured by bioimpedentiometry (Sta/BIA Akern, Florence, Italy) and respiratory quotient (RQ) and basal metabolic rate (BMR) by indirect calorimetry (Sensor Medics Vmax29, Anaheim, CA, USA). The BMI was calculated as weight $(\mathrm{kg})$ /square height $\left(\mathrm{m}^{2}\right)$. Systolic and diastolic blood pressure, and cardiac frequency (beats/min) were collected by standard procedures. Metabolic syndrome (MS), which is a cluster of metabolic risk factors, namely, abdominal obesity, dyslipidemia (hypertriglyceridemia or low HDL-cholesterol concentrations), elevated blood pressure, and hyperglycemia, as defined by the American Heart Association criteria, was diagnosed if 3 out of the 5 risk factors were present [20].

\subsection{Mitochondrial DNA Amplification and Sequencing.} Genomic DNA was extracted from whole blood (Illustra BACC-2; GE Healthcare, UK). The D-loop region (about $1100 \mathrm{bp}$ ) was amplified with primers (HVI-forward: GTAAACCGGAGATGAAAACCT; HVII-reverse ACTGCATACCGCCAAAAGATA) chosen by the PRIMER 3 program (http://frodo.wi.mit.edu/) in a final volume of $25 \mu \mathrm{L}$ containing a PCR mixture $(10 \mu \mathrm{M}$ each primer, $10 \mathrm{x}$ PCR buffer, $200 \mu \mathrm{M}$ each deoxynucleotide triphosphate, and $0.5 \mathrm{U}$ of Taq DNA polymerase) and $50 \mathrm{ng}$ of genomic DNA. PCR consisted of an initial denaturation at $95^{\circ} \mathrm{C}$ for $5 \mathrm{~min}$, followed by 35 cycles of $95^{\circ} \mathrm{C}$ for $30 \mathrm{~s}, 60^{\circ} \mathrm{C}$ for $1 \mathrm{~min}$, and $72^{\circ} \mathrm{C}$ for $1 \mathrm{~min}$, followed by a final extension at $72^{\circ} \mathrm{C}$ for $5 \mathrm{~min}$. The PCR fragment was run on a $1.5 \%$ agarose gel, purified, and sequenced in both directions (BigDye Terminator v3.1 cycle sequencing method on an ABI-Prism 3730 DNA Analyzer; Applied Biosystems). Sequences were assembled with the SeqScape program v.2.5. The mtDNA nucleotide sequences were numbered according to the rCRS reference sequence (NC_012920). Haplogroups were defined by nucleotides at specific known polymorphic sites in the mtDNA [6].

2.4. Statistical Analysis. Haplogroup frequencies in patients and control subjects were compared using the $\chi^{2}$ test. A $P<0.05$ was considered the level of statistical significance. The odds ratio (OR) and $95 \%$ confidence intervals (CI) values for each haplogroup were calculated for the statistically significant haplogroup. ANOVA was performed to compare metabolic parameters in the different haplogroups. Multiple comparisons were corrected with the Bonferroni test. The Student's $t$-test, followed by a binomial logistic regression analysis, was used to investigate the association between the biochemical and clinical characteristics and the presence/absence of a specific haplogroup. Sample estimates were verified by bootstrapping. Statistical analyses were carried out with the PASW package for Windows (Ver.18; SPSS Inc. Headquarters, Chicago, Il, USA).

\section{Results}

The clinical and biochemical characteristics of the obese subjects are reported in Table 1. Metabolic syndrome was present in $41.3 \%$ of our obese subjects and was significantly more frequent in men than in women (47.9\% versus $37.5 \%$; OR/95\% $\mathrm{CI}=1.17 / 1.01-1.35, P=0.031)$. Concurrent MS factors in our obese patients were hypertriglyceridemia (OR/95\% CI: 16.7/10.8-26.0), hyperglycemia (OR/95\% CI: 8.5/5.6-12.8), hypertension (OR/95\% CI: 7.1/4.7-10.7), low serum levels of HDL cholesterol (OR/95\% CI: 5.1/3.6-7.4). Haplogroup frequencies in obese and nonobese subjects are reported in Table 2. All nine common European haplogroups ( H, I, J, $\mathrm{K}, \mathrm{T}, \mathrm{U}, \mathrm{V}, \mathrm{W}$, and $\mathrm{X}$ ) [21] were identified in most of our subjects $(94.4 \%)$, whereas the R, L, N, B, and F haplogroups (collectively indicated as "others" in Table 2) were rare (5.6\%). 
European haplogroup frequencies were very similar in our obese and nonobese subjects, and the $\mathrm{H}$ haplogroup was the most frequent (about $40 \%$ of subjects). The T $(P=0.004)$ and $\mathrm{J}(P=0.02)$ haplogroup frequencies were higher and lower, respectively, in obese subjects than in controls (haplogroup T: $13.2 \%$ versus $6 \%$; haplogroup J: $5 \%$ versus $9.7 \%$ ). At the $\chi^{2}$ test, subjects with the Thaplogroup had an increased risk of about two-fold for obesity (OR/95\% CI $=1.94 / 1.16-3.22 ; P=0.004)$, whereas subjects with the $\mathrm{J}$ haplogroup were less exposed to obesity $(\mathrm{OR} / 95 \% \mathrm{CI}=0.63 / 0.45-0.89 ; P=0.02)$ than subjects with the other haplogroups. These findings were confirmed by the results of bootstrap analysis based on 100 bootstrap samples.

When we divided our populations into males and females, the prevalence of the $\mathrm{T}$ and $\mathrm{J}$ haplogroups remained significantly higher and lower, respectively, in the obese females $(12.4 \%$ versus $4.9 \%$, OR/95\% $\mathrm{CI}=2.18 / 1.01-4.39 ; P=0.012$ for haplogroup $\mathrm{T} ; 4.7 \%$ versus $11.9 \%$, OR/95\% CI $=0.55 / 0.38-$ $0.78 ; P=0.009$ for haplogroup J). In addition, the $\mathrm{T}$ haplogroup was correlated to the degree of obesity. In fact, this haplogroup was significantly more frequent in obese subjects with a BMI higher than in those with a BMI lower than the median BMI $\left(45 \mathrm{~kg} / \mathrm{m}^{2}\right)$ (16\% versus $10 \%$, resp.; $P=0.04$ ). Binomial logistic regression analysis (dependent variable: median BMI and independent variables: clinical and biochemical investigated parameters) showed that haplogroup $\mathrm{T}$ and systolic blood pressure are risk factors for a high degree of morbid obesity, namely, BMI $>45 \mathrm{~kg} / \mathrm{m}^{2}$ (OR/95\% CI: 2.3/1.3-4.3 and OR/95\% CI: 1.1/1.02-1.4, resp.); in fact together they account for $8 \%$ of the BMI. We did not find an association between mtDNA haplogroups and the clinical/biochemical tested variables, or in haplogroup frequencies according to MS presence/absence.

\section{Discussion}

Mitochondrial DNA haplogroups have been associated with metabolic disorders in various populations [3, 22, 23], although not yet in morbid obese Caucasians from southern Italy. The prevalence of MS in our obese patients (41\%) was similar to that previously reported in a multicenter Italian study (43.6\%) [24]. We found that haplogroup $\mathrm{H}$ was the most common haplogroup in both obese and control subjects ( $46.6 \%$ and $40.7 \%$, resp.) from southern Italy, which is in agreement with the $\mathrm{H}$ frequency reported in other European populations (haplogroup H frequency: $13.3 \%-41.7 \%$ ) [21]. We also show that haplogroups $\mathrm{T}$ and $\mathrm{J}$ conferred an increased and decreased risk for obesity, respectively. The J haplogroup was reported to protect against the onset of diseases related to oxidative stress and/or low inflammation grade, such as ischemic cardiomyopathy [25]. In fact, subjects bearing this haplogroup showed lower oxygen consumption (because the lower efficiency of the electron respiratory chain resulted in reduced production of radical oxygen species) than those with the $\mathrm{H}$ haplogroup [25].

On the other hand, subjects with haplogroup T could be intrinsically prone to develop defects in the mitochondrial oxidative phosphorylation system, which, in turn, negatively
TABLE 1: General and biochemical characteristics of the morbid obese patients studied $(n=500)$.

\begin{tabular}{|c|c|c|c|}
\hline & \multirow{2}{*}{ Median } & \multicolumn{2}{|c|}{ Percentiles } \\
\hline & & 2.5 th & 97.5th \\
\hline Age (years) & 32.59 & 17.50 & 57.00 \\
\hline Height (m) & 1.66 & 1.51 & 1.85 \\
\hline Weight (kg) & 125.54 & 98.00 & 178.40 \\
\hline BMI $\left(\mathrm{kg} / \mathrm{m}^{2}\right)$ & 45.10 & 38.20 & 65.40 \\
\hline Waist circumference $(\mathrm{cm})$ & 131.00 & 106.00 & 170.00 \\
\hline Hips circumference $(\mathrm{cm})$ & 134.00 & 114.90 & 158.10 \\
\hline $\mathrm{W} / \mathrm{H}$ ratio & 0.99 & 0.82 & 1.19 \\
\hline RQ & 0.87 & 0.74 & 1.01 \\
\hline BMR (kcal) & 2237.50 & 1581.38 & 3278.63 \\
\hline FFM (\%) & 51.40 & 40.28 & 64.11 \\
\hline $\mathrm{FM}(\%)$ & 48.55 & 35.89 & 59.73 \\
\hline SBP (mmHg) & 124.45 & 100.00 & 160.00 \\
\hline DBP (mmHg) & 80.00 & 60.00 & 100.00 \\
\hline Heart rate (beats/min) & 80.00 & 60.00 & 100.00 \\
\hline Glucose $(\mathrm{mmol} / \mathrm{L})$ & 5.05 & 3.89 & 7.53 \\
\hline Total cholesterol $(\mathrm{mmol} / \mathrm{L})$ & 4.75 & 3.11 & 7.12 \\
\hline HDL cholesterol (mmol/L) & 1.21 & 0.73 & 1.82 \\
\hline Triglycerides (mmol/L) & 1.42 & 0.56 & 3.16 \\
\hline $\operatorname{AST}(\mathrm{U} / \mathrm{L})$ & 23.00 & 13.55 & 64.45 \\
\hline $\operatorname{ALT}(\mathrm{U} / \mathrm{L})$ & 31.00 & 12.00 & 84.45 \\
\hline GGT (U/L) & 26.00 & 10.00 & 87.50 \\
\hline $\mathrm{CHE}(\mathrm{U} / \mathrm{mL})$ & 10066.37 & 5828.90 & 15084.55 \\
\hline Total bilirubin $(\mu \mathrm{mol} / \mathrm{L})$ & 9.41 & 4.28 & 20.94 \\
\hline Uric acid (mmol/L) & 0.35 & 0.21 & 0.57 \\
\hline Albumin (g/dL) & 4.30 & 3.60 & 4.90 \\
\hline Total Protein (g/dL) & 7.56 & 6.76 & 8.30 \\
\hline Creatinine $(\mu \mathrm{mol} / \mathrm{L})$ & 70.72 & 44.20 & 106.08 \\
\hline Urea $(\mathrm{mmol} / \mathrm{L})$ & 5.33 & 3.33 & 8.16 \\
\hline $\operatorname{ALP}(\mathrm{U} / \mathrm{L})$ & 76.00 & 42.75 & 247.75 \\
\hline C-peptide (ng/mL) & 3.90 & 1.80 & 7.35 \\
\hline Insulin (mU/L) & 19.00 & 6.90 & 53.03 \\
\hline HOMA & 4.26 & 1.43 & 14.66 \\
\hline
\end{tabular}

ALP: alkaline phosphatase; ALT: alanine transaminase; AST: aspartate transaminase; BMI: Body Mass Index; BMR: basal metabolic rate; CHE: cholinesterase; DBP: diastolic blood pressure; FFM: fat-free mass; FM: fat mass; GGT: $\gamma$-glutamyl transferase; HOMA: homeostatic model assessment; RQ: respiratory quotient; SBP: systolic blood pressure; W/H: waist/hip.

affects the performance of mitochondrial ATP production [11]. In fact, haplogroup $\mathrm{T}$ was reported to be more frequent in white men with fertility problems (a condition strongly dependent on ATP production) [13] and among Spanish patients affected by left ventricular hypertrophy [26]. Indeed, haplogroup $\mathrm{T}$ was less frequent among elite endurance athletes (possibly related to a negative effect on cardiac adaptation to endurance training) [11]. Amo et al. [27] reported that mitochondrial bioenergetic capacities and coupling efficiencies in cultured carcinoma cells did not differ between transmitochondrial cybrids harbouring mitochondria with haplogroup $\mathrm{H}$ and those harbouring mitochondria with haplogroup $\mathrm{T}$ [27]. However, the authors suggest that 
TABLE 2: Haplogroup frequencies in morbid obese patients $(n=$ $500)$ and controls $(n=216)$.

\begin{tabular}{lcccc}
\hline Haplogroup & $\begin{array}{c}\text { Obese } \\
\text { patients } n(\%)\end{array}$ & $\begin{array}{c}\text { Control } \\
\text { subjects } n(\%)\end{array}$ & $P$ & OR/95\% CI \\
\hline $\mathrm{H}$ & $233(46.6)$ & $88(40.7)$ & & \\
$\mathrm{I}$ & $7(1.4)$ & $6(2.8)$ & & \\
$\mathrm{J}$ & $25(5.0)$ & $21(9.7)$ & 0.02 & $0.63 / 0.45-0.89$ \\
$\mathrm{~K}$ & $29(5.8)$ & $18(8.3)$ & & \\
$\mathrm{T}$ & $66(13.2)$ & $13(6.0)$ & 0.004 & $1.94 / 1.16-3.22$ \\
$\mathrm{JT}$ & $0(0)$ & $1(0.5)$ & & \\
$\mathrm{U}$ & $85(17.0)$ & $39(18.1)$ & & \\
$\mathrm{V}$ & $13(2.6)$ & $4(1.9)$ & & \\
$\mathrm{W}$ & $8(1.6)$ & $2(0.9)$ & & \\
$\mathrm{X}$ & $10(2.0)$ & $8(3.7)$ & & \\
Others & $24(4.8)$ & $16(7.4)$ & & \\
\hline
\end{tabular}

this result could be partially inconclusive because the effect of mitochondrial haplogroups might be too small to be detected by the procedures used [27], or they might need particular nuclear genes in order to be expressed, or they might need additional signals (nutrients and/or oxidative stress molecules) to influence oxidative phosphorylation functions, as previously described for the Uk haplogroup [28]. The foregoing studies suggest that, in our obese patients, the $\mathrm{T}$ haplogroup could contribute to affect the mechanisms of energy balance regulation so leading to increased fat depots.

In conclusion, our finding that haplogroup $\mathrm{T}$ increases the risk of obesity by about two-fold suggests that, besides nuclear genome variations and environmental factors, the $\mathrm{T}$ haplogroup contributes to morbid obesity in our study population from southern Italy.

\section{Conflict of Interests}

The authors have no conflict of interests to declare.

\section{Acknowledgments}

The authors thank Jean Ann Gilder (Scientific Communication srl, Naples, Italy) for text revision and editing. This work was supported by Grants Conv. CEINGE-Regione Campania (DGRC 1901/2009), IRCCS Fondazione SDN, Ministry of Health, and POR Campania FSE 2007-2013, Project CREME.

\section{References}

[1] J. S. El-Sayed Moustafa and P. Froguel, "From obesity genetics to the future of personalized obesity therapy," Nature Reviews. Endocrinology, vol. 9, no. 7, pp. 402-13, 2013.

[2] J. C. Bournat and C. W. Brown, "Mitochondrial dysfunction in obesity," Current Opinion in Endocrinology, Diabetes and Obesity, vol. 17, no. 5, pp. 446-452, 2010.

[3] T.-L. Yang, Y. Guo, H. Shen et al., "Genetic association study of common mitochondrial variants on body fat mass," PLoS One, vol. 6, no. 6, Article ID e21595, 2011.
[4] R. Liguori, C. Mazzaccara, F. Pasanisi et al., “The mtDNA 15497 G/A polymorphism in cytochrome b in severe obese subjects from Southern Italy," Nutrition, Metabolism and Cardiovascular Diseases, vol. 16, no. 7, pp. 466-470, 2006.

[5] N. Pichaud, J. W. Ballard, R. M. Tanguay, and P. U. Blier, "Naturally occurring mitochondrial DNA haplotypes exhibit metabolic differences: insight into functional properties of mitochondria," Evolution, vol. 66, no. 10, pp. 3189-3197, 2012.

[6] A. Torroni, K. Huoponen, P. Francalacci et al., "Classification of european mtDNAs from an analysis of three European populations," Genetics, vol. 144, no. 4, pp. 1835-1850, 1996.

[7] D. M. Behar, R. Villems, H. Soodyall et al., "The dawn of human matrilineal diversity," American Journal of Human Genetics, vol. 82, no. 5, pp. 1130-1140, 2008.

[8] D. Mishmar, E. Ruiz-Pesini, P. Golik et al., "Natural selection shaped regional mtDNA variation in humans," Proceedings of the National Academy of Sciences of the United States of America, vol. 100, no. 1, pp. 171-176, 2003.

[9] E. Ruiz-Pesini, D. Mishmar, M. Brandon, V. Procaccio, and D. C. Wallace, "Effects of purifying and adaptive selection on regional variation in human mtDNA," Science, vol. 303, no. 5655, pp. 223-226, 2004.

[10] M. A. Abdul-Ghani and R. A. DeFronzo, "Mitochondrial dysfunction, insulin resistance, and type 2 diabetes mellitus," Current Diabetes Reports, vol. 8, no. 3, pp. 173-178, 2008.

[11] M. G. Castro, N. Terrados, J. R. Reguero, V. Alvarez, and E. Coto, "Mitochondrial haplogroup $\mathrm{T}$ is negatively associated with the status of elite endurance athlete," Mitochondrion, vol. 7, no. 5, pp. 354-357, 2007.

[12] P. G. Ridge, T. J. Maxwell, C. D. Corcoran et al., "Mitochondrial genomic analysis of late onset Alzheimer's disease reveals protective haplogroups H6A1A/H6A1B: the Cache County Study on Memory in Aging," PLoS One, vol. 7, no. 9, Article ID e45134, 2012.

[13] E. Ruiz-Pesini, A. C. Lapeña, C. Díez-Sánchez et al., "Human mtDNA haplogroups associated with high or reduced spermatozoa motility," American Journal of Human Genetics, vol. 67, no. 3, pp. 682-696, 2000.

[14] R. Martinelli, C. Nardelli, V. Pilone et al., "MiR-519d overexpression Is associated with human obesity," Obesity, vol. 18, no. 11, pp. 2170-2176, 2010.

[15] V. Capobianco, C. Nardelli, M. Ferrigno et al., "MiRNA and protein expression profiles of visceral adipose tissue reveal miR-141/YWHAG and miR-520e/RAB11A as two potential miRNA/protein target pairs associated with severe obesity," Journal of Proteome Research, vol. 11, no. 6, pp. 3358-3369, 2012.

[16] R. Bracale, G. Labruna, C. Finelli et al., "The absence of polymorphisms in ADRB3, UCP1, PPAR $\gamma$, and ADIPOQ genes protects morbid obese patients toward insulin resistance," Journal of Endocrinological Investigation, vol. 35, no. 1, pp. 2-4, 2012.

[17] G. Labruna, F. Pasanisi, C. Nardelli et al., "UCP1 -3826 AG+GG genotypes, adiponectin, and leptin/adiponectin ratio in severe obesity," Journal of Endocrinological Investigation, vol. 32, no. 6, pp. 525-529, 2009.

[18] L. Iaffaldano, C. Nardelli, M. Raia et al., "High aminopeptidase N/CD13 levels characterize human amniotic mesenchymal stem cells and drive their increased adipogenic potential in obese women," Stem Cells and Development, 2013.

[19] D. Ghezzi, C. Marelli, A. Achilli et al., "Mitochondrial DNA haplogroup $\mathrm{K}$ is associated with a lower risk of parkinson's 
disease in Italians," European Journal of Human Genetics, vol. 13, no. 6, pp. 748-752, 2005.

[20] S. M. Grundy, J. I. Cleeman, S. R. Daniels et al., "Diagnosis and management of the metabolic syndrome: an American Heart Association/National Heart, Lung, and Blood Institute scientific statement," Circulation, vol. 112, no. 17, pp. 2735-2752, 2005.

[21] A. Torroni, M. Richards, V. Macaulay et al., "mtDNA haplogroups and frequency patterns in Europe," American Journal of Human Genetics, vol. 66, no. 3, pp. 1173-1177, 2000.

[22] L.-J. Guo, Y. Oshida, N. Fuku et al., "Mitochondrial genome polymorphisms associated with type-2 diabetes or obesity," Mitochondrion, vol. 5, no. 1, pp. 15-33, 2005.

[23] M. Tanaka, N. Fuku, Y. Nishigaki et al., "Women with mitochondrial haplogroup N9a are protected against metabolic syndrome," Diabetes, vol. 56, no. 2, pp. 518-521, 2007.

[24] G. Marchesini, N. Melchionda, G. Apolone et al., "The metabolic syndrome in treatment-seeking obese persons," Metabolism, vol. 53, no. 4, pp. 435-440, 2004.

[25] M. Fernández-Caggiano, J. Barallobre-Barreiro, I. Rego-Pérez et al., "Mitochondrial haplogroups $\mathrm{H}$ and J: risk and protective factors for ischemic cardiomyopathy," PLoS One, vol. 7, no. 8, Article ID e44128, 2012.

[26] M. G. Castro, C. Huerta, J. R. Reguero et al., "Mitochondrial DNA haplogroups in Spanish patients with hypertrophic cardiomyopathy," International Journal of Cardiology, vol. 112, no. 2, pp. 202-206, 2006.

[27] T. Amo, N. Yadava, R. Oh, D. G. Nicholls, and M. D. Brand, "Experimental assessment of bioenergetic differences caused by the common European mitochondrial DNA haplogroups $\mathrm{H}$ and T,' Gene, vol. 411, no. 1-2, pp. 69-76, 2008.

[28] A. Gómez-Durán, D. Pacheu-Grau, E. López-Gallardo et al., "Unmasking the causes of multifactorial disorders: OXPHOS differences between mitochondrial haplogroups," Human Molecular Genetics, vol. 19, no. 17, pp. 3343-3353, 2010. 

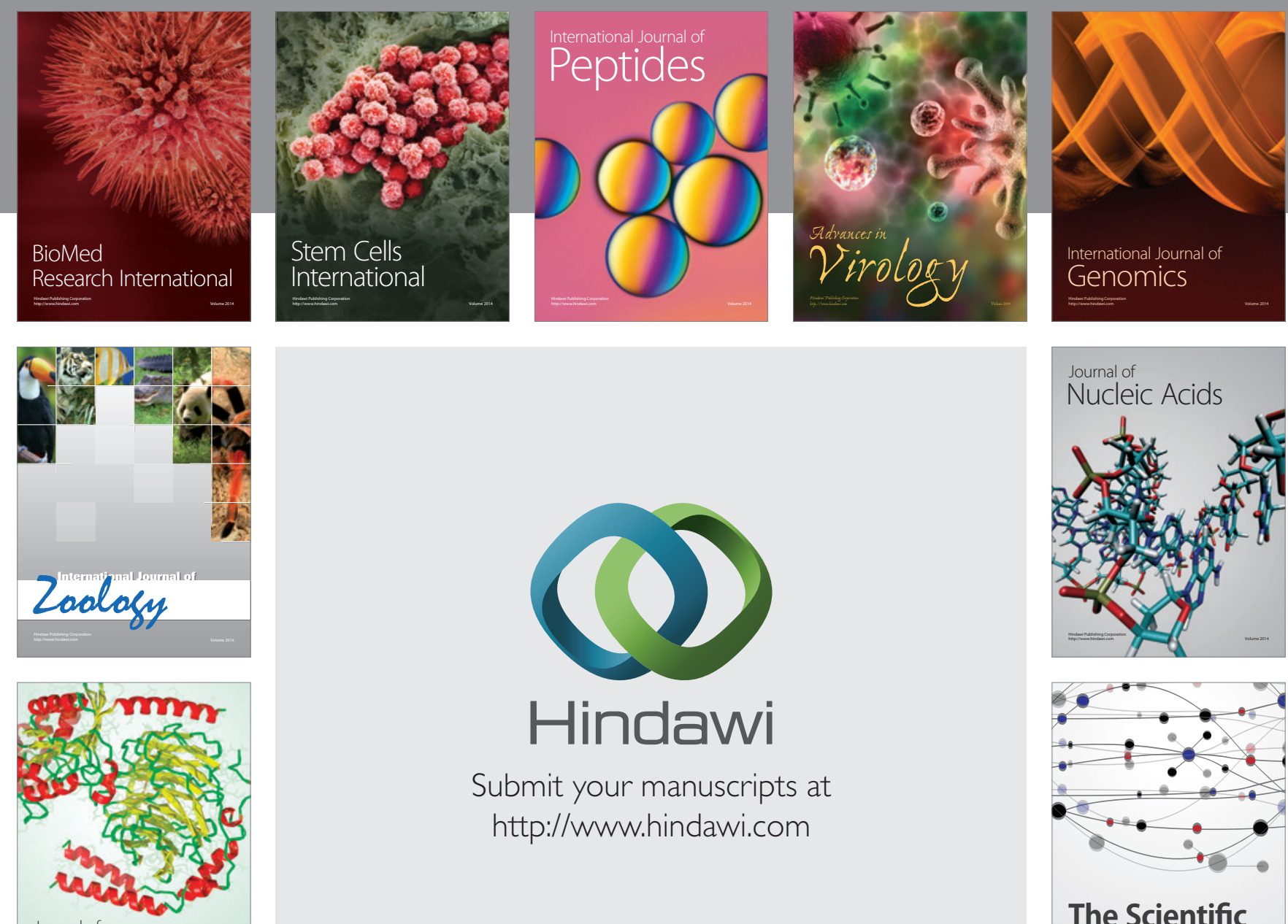

Submit your manuscripts at

http://www.hindawi.com

Journal of
Signal Transduction
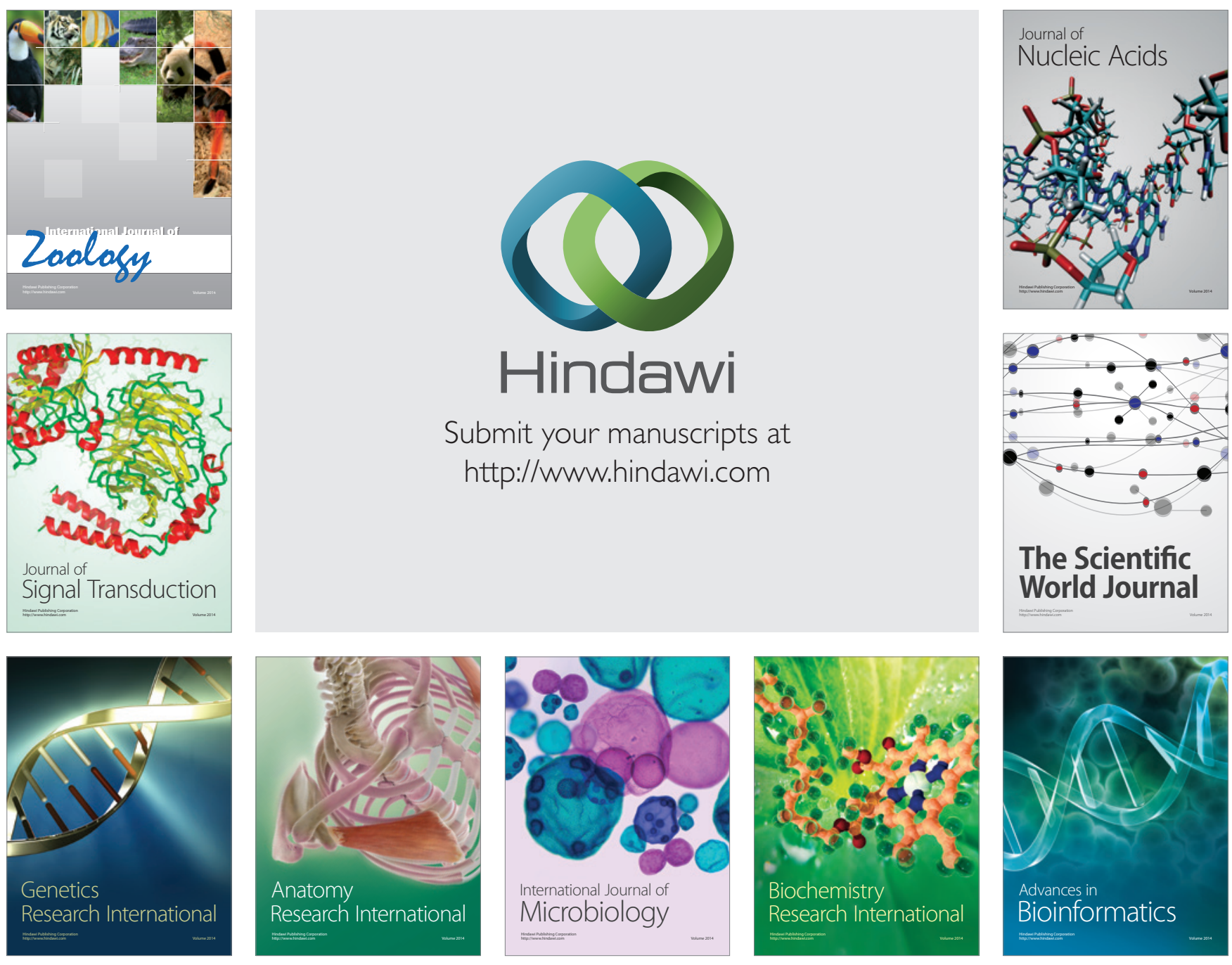

The Scientific World Journal
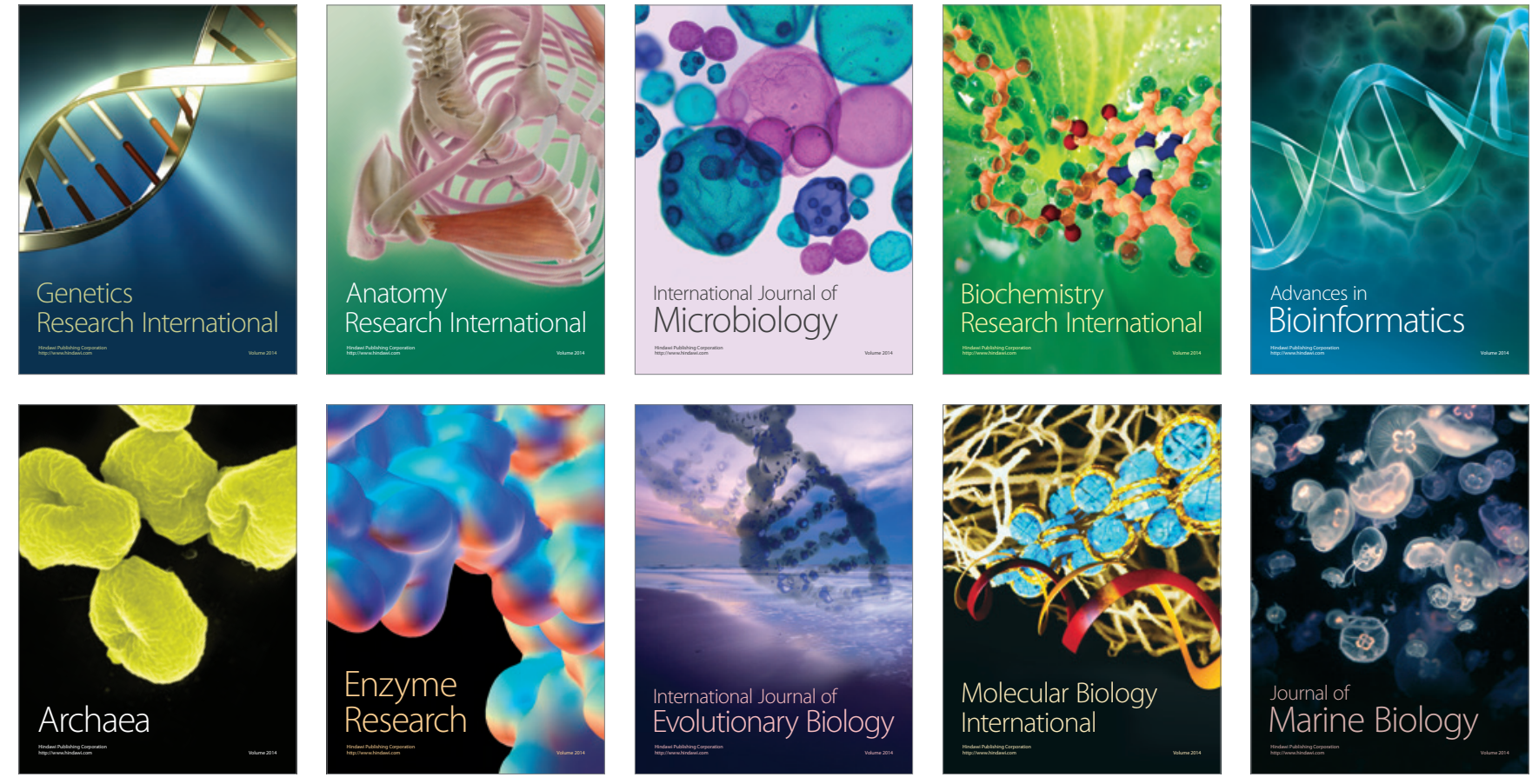